\title{
ANÁLISE DO PROGRAMA DE LICENCIATURA INTERNACIONAL (PLI) NO CONTEXTO DA INTERNACIONALIZAÇÃO DA EDUCAÇÃO SUPERIOR
}

\author{
Nayara Christine Souza ${ }^{1}$ \\ Gabriel Humberto Muñoz Palafox²
}

\begin{abstract}
Resumo
O objetivo do presente trabalho é descrever e analisar aspectos da internacionalização da educação superior brasileira no contexto da globalização, e sua relação específica com a política desenvolvida no período 2010-2012 pelo Programa de Licenciatura Internacional (PLI), instituído oficialmente em 2010 pela CAPES. Para tanto, foi realizada uma análise quanti-qualitativa com base em pesquisa documental e bibliográfica. Em tese, as próprias Instituições de Ensino Superior (IES) avaliam internamente o impacto da vivência dos discentes na sua formação profissional. Entretanto, os critérios avaliativos do processo não são contemplados nos editais publicados pela CAPES, deixando em aberto e ambíguo os resultados esperados, para além do quantitativo de professores e discentes envolvidos no processo.
\end{abstract}

Palavras- chaves: Internacionalização. Globalização. Ensino Superior.

\section{ANALYSIS OF THE INTERNACIONAL LICENCIATE DEGREE PROGRAM IN THE CONTEXT OF THE HIGHER EDUCATION INTERNATIONALIZATION}

\begin{abstract}
The objective of this study is to describe and analyze aspects of Brazilian higher education internationalization in the context of globalization and its specific relationship with the policy implemented in the period 2010-2012 by the International Licentiate Degree Program (PLI in Portuguese acronym), officially established in 2010 by CAPES. Thereunto, quantitative and qualitative analysis was carried out, based on documentary and bibliographic research. In theory, the own Higher Education Institutions internally assess the impact of the experience of students in their professional training. However, the assessment criteria of the process are not covered by the notices published by CAPES, leaving open and ambiguous the expected results, in addition to the quantity of teachers and students involved.
\end{abstract}

Keywords: Internationalization. Globalization. Higher Education.

\section{ANÁLISIS DE GRADO PROGRAMA INTERNACIONAL (PLI) EN EL CONTEXTO DE LA INTERNACIONALIZACIÓN EDUCACIÓN SUPERIOR}

\section{Resumen \\ El objetivo de este estudio es describir y analizar aspectos de la internacionalización brasileña educación superior en el contexto de la globalización y su relación específica con la política aplicada en el periodo 2010-2012 por el Programa de Licenciatura Internacional (ILP), establecida oficialmente en 2010 por la CAPES. Por lo tanto, se llevó a cabo un análisis cuantitativo y cualitativo basado en el

\footnotetext{
1 Mestranda em Educação pela Universidade Federal de Uberlândia -UFU. E-mail: $<$ nayara christine@hotmail.com>.

2 Doutor em Educação e Professor da Universidade Federal de Uberlândia- UFU. E-mail: <gabmpalafox@hotmail.com..
} 
documental y la investigación bibliográfica. En teoría, sus propias instituciones de educación superior (IES) evaluar internamente el impacto de la experiencia de los estudiantes en su formación profesional. Sin embargo, los criterios de evaluación del proceso no están cubiertos por los avisos publicados por la CAPES, dejando abiertas y ambiguas los resultados esperados, además de la cantidad de profesores y estudiantes que participan en el proceso.

Palabras- Claves: La internacionalización. Globalización. Enseñanza Superior.

\section{Introdução}

As políticas neoliberais, que ganharam notoriedade no século XX, vêm refletindo e influenciando diretamente os sistemas educacionais de todos os Estados nacionais e, em particular, aqueles relacionados diretamente com as instituições de ensino superior (IES). Parte dos impactos ocorridos nos sistemas de educação superior refere-se justamente à necessidade de serem atendidas as demandas de formação profissional que o sistema capitalista demanda, motivo pelo qual diretrizes, políticas e leis vêm sendo promulgadas e implementadas por órgãos internacionais e adaptadas localmente, tendo em vista atender às conjunturas econômicas impostas, fundamentalmente, pelo mundo do trabalho globalizado, em nível mundial.

Nesse contexto, no período 1990-2000, vários acordos e pactos internacionais foram assinados para colocar em prática uma série de políticas de intercâmbio acadêmico e profissional, destacando-se, dentre estes, a assinatura da Declaração de Bolonha (1999), entre ministros da educação de 29 Estados Europeus. Esta iniciativa consolidou as bases para a construção do Espaço Europeu de Educação Superior (EEES), tendo como prioridades favorecer a empregabilidade e a competitividade internacional do sistema europeu de educação superior.

No que diz respeito à América Latina, no meio de conflitos decorrentes da resistência do meio acadêmico a parte das propostas de formação profissional, influenciadas pelos órgãos supranacionais que, dentre outros aspectos, parecem afetar a denominada autonomia didático-pedagógica das universidades, o Brasil é um dos países que, ao longo dos séculos $\mathrm{XX}$ e XXI, começou a formular e implementar políticas educacionais destinadas à internacionalização da educação superior. Tais políticas, s para pesquisadores como Stallivieri (2004), vêm ocorrendo de forma acelerada, implicando, com isto, na procura de espaços institucionais capazes de responder à conjuntura imposta, mais efetivamente, nos níveis de atuação científica e tecnológica. 
De acordo com Miura (2009), os termos globalização e internacionalização de Ensino Superior, muitas vezes, são usados como sinônimos, e existe uma ampla discussão acerca deles. Todavia, apesar de serem processos intimamente relacionados, é importante enfatizar as diferenças, distanciamentos e as relações existentes entre ambos os termos.

O termo globalização, para Knight e De Wit (1997, p. 2), define-se como "o fluxo de tecnologia, economia, conhecimento, gente, valores e ideias, além das fronteiras", o qual afeta a cada país de maneira diferente, devido à história individual de uma nação, suas tradições, cultura e prioridades.

A definição do termo globalização é considerada uma

[...] palavra amorfa, tenta expressar a constituição da aldeia global no seu processo de desenvolvimento contínuo, onde há intensificação e diversificação de fluxos de pessoas, bens, serviços, capitais, tecnologias e ideias. Ressalta ainda, que os outros termos como mundialização, internacionalização e transnacionalização são usados para expressar e salientar determinados aspectos da globalização: cultura e cidadania na mundialização; relações comerciais entre nações na internacionalização; e os agentes que extravasam as fronteiras nacionais na transnacionalização. (ZAMBERLAN et al. 2009, p. 17).

Nesse sentindo, o termo globalização não se restringe apenas a uma área, mas abrange diversos aspectos relacionados entre eles: ciências e tecnologia, economia, comunicação, cultura, política e a educação.

Cabe salientar que o termo relativo à internacionalização da educação superior possui uma gama de definições.

Por exemplo, pode-se afirmar que a internacionalização do ensino superior é

[...] um processo de mudanças organizacionais, de inovação curricular, de desenvolvimento profissional do corpo acadêmico e da equipe administrativa, de desenvolvimento da mobilidade acadêmica com a finalidade de buscar a excelência na docência, na pesquisa e em outras atividades que são parte da função das universidades (STALLIVIERI, 2008, p. $5)$.

Para Altbach (2004 p. 3), o termo internacionalização corresponde às "políticas especificas e programas sob responsabilidades de governos, sistemas acadêmicos e instituições, e mesmo departamentos e instituições individuais para se adaptar ou explicar a 
globalização". Partindo deste viés, a internacionalização das IES e dos governos são autônomas e voluntárias, pois decidem como lidar no contexto da globalização.

Os autores Altbach e Knight (2007) ressaltam a diferença de globalização e internacionalização, na qual aquele está ligado com o contexto de tendências econômicas e acadêmicas do século XXI. Por outro lado, a este trata do conjunto de políticas e práticas empreendidas por sistemas acadêmicos, instituições e indivíduos para lidar com o ambiente acadêmico global. Entretanto, diante de divergências identificadas entre os conceitos de globalização e internacionalização, Souza (2010) afirma que a globalização é um fenômeno, ligado não somente à educação, mas à economia e cultura. No entanto, a internacionalização é relativa às práticas exercidas no âmbito da educação por governos e instituições, visando à mobilidade e/ou transferência de conhecimento do sistema educacional de um Estado para o sistema de outro Estado.

Para Altbach e Knight (2007, p. 291), “A globalização pode ser inalterável, mas a internacionalização envolve muitas escolhas". No contexto da globalização, a história da internacionalização da educação superior é um processo complexo, com implicações políticas, econômicas, culturais e sociais para os países, as instituições e pessoas envolvidas.

De alguma forma, esta necessidade surgiu no próprio cenário mundial, em consonância com o fenômeno de expansão do capital (VIDAL, 2006), o qual tem provocado grandes transformações econômicas, culturais e geopolíticas e, principalmente, educacionais em todo mundo.

Nesse contexto, o que de certa forma pode ser presenciado é o desaparecimento ou relativização (ainda que virtual), das fronteiras entre as nações. Uma forma de globalização que, em tese, pode/está enfraquecendo gradativamente a estrutura, funcionamento e cultura dos Estados-Nacionais, ou a dar-lhes novas formas e funções (VIDAL, 2006).

Diante das exigências do capital, o mundo do trabalho vem exigindo, dos indivíduos, a adoção de novas competências profissionais e preparação qualificada, seja por meio do conhecimento de outras línguas, culturas, experiência ou mesmo a aprendizagem adquirida no processo de formação acadêmica.

Nesse contexto da internacionalização, optou-se por analisar o Programa de Licenciatura Internacional (PLI), que faz parte das políticas educacionais da Coordenação de Aperfeiçoamento de Pessoal de Nível Superior (CAPES), implementada no ano de 2010. Ao se 
tratar da CAPES, faz-se necessário uma breve retrospectiva histórica para compreender os motivos que levaram a financiar o programa em estudo.

Na década de 1950, o Decreto no 29.741, em 11 de julho instituiu uma Comissão, na esfera do Ministério da Educação, para promover a Campanha Nacional de Aperfeiçoamento de Pessoal de Nível Superior, o que conhecemos hoje como Capes. Desde o início, a Capes esteve presente no ensino e na pesquisa vinculados às instituições de ensino superior. Nesse contexto, ao longo dos anos foram criados inúmeros programas nas agências nacionais de fomento, com o objeto da qualificação do pesquisadores e docentes do ensino superior.

Avançando no tempo, no ano de 2007, o Congresso Nacional aprovou a Lei n¹1.502/2007, homologada pelo o presidente Luiz Inácio Lula da Silva, que modificou as competências e as estruturas organizacionais da Capes. Além disso, autorizou a concessão de bolsa de estudo e pesquisa para participantes de programas de formação inicial e continuada de professores para a Educação Básica. Nesse sentindo, a Capes induz e fomenta, inclusive em regime de colaboração com os Estados, os Municípios, e o Distrito Federal e exclusivamente mediante convênios com instituições de ensino superior públicas ou privadas, a formação inicial e continuada no magistério, respeitada a liberdade acadêmica das instituições conveniadas.

Diante disso, a Capes tem subsidiado um conjunto de programas destinado à implementação de políticas públicas de incentivo à formação inicial do professor, como o Programa de Consolidação das Licenciaturas (PRODOCÊNCIA), Programa Institucional de Bolsa de Iniciação à Docência (PIBID), Programa de Apoio a Laboratórios Interdisciplinares de Formação de Educadores (LIFE), e o Programa de Licenciaturas Internacionais (PLI), este último é foco do estudo.

O PLI teve sua primeira edição em 2010, com o objetivo de ampliar as ações voltadas para a formação inicial do professor para atuar na Educação Básica, buscando elevar a qualidade da graduação, e tendo como prioridade a melhoria do ensino dos cursos de licenciatura e a formação de professores. Este programa prevê, entre outros resultados, uma dupla certificação a ser emitida pela instituição brasileira e pela portuguesa (BRASIL, 2010, 2011, 2012). 
O Programa em estudo foi criado com o apoio do Grupo de Coimbra de Universidades Brasileiras (GCUB) ${ }^{3}$ e é financiado e desenvolvido pela Capes. O GCUB tem por objetivos:

Promover estruturas de cooperação nas áreas da ciência, tecnologia e inovação, fomentando a organização de redes de investigação orientadas para projetos de valor estratégico; garantir o reconhecimento recíproco dos títulos e graus acadêmicos obtidos nas instituições dirigidas pelos seus associados; promover a internacionalização das universidades; estimular e facilitar a mobilidade de professores, de estudantes e de quadros superiores da administração das Universidades (GCUB, 2015, p. 14).

O PLI é um programa institucional e, por esta razão, a submissão de propostas é feita pelas instituições de ensino superior brasileiras e não por demanda direta dos estudantes. Os projetos aprovados contemplam não só os alunos, também professores doutores, que têm a responsabilidade de orientar e acompanhar o desenvolvimento dos grupos de estudantes antes, durante e após o período de permanência no exterior. Entre tais projetos decorrentes dos editais, editado e reeditado nos anos de 2010 a 2012 para a candidatura da proposta por parte das IES, levamos em consideração o edital de 2012, no qual

A instituição brasileira poderá submeter sete propostas de caráter institucional que poderão ser disciplinares ou multidisciplinares (voltadas para mais de uma das áreas referidas); Uma mesma proposta para diferentes universidades portuguesas, incluindo coordenador, membros da equipe de trabalho e/ou estudantes, não poderá ser apresentada neste edital. Esse procedimento levará à eliminação da inscrição; Coordenadores e membros de equipe de projetos vigentes poderão apresentar nova proposta para novos bolsistas; A instituição brasileira deverá possuir Acordo Geral de

\footnotetext{
${ }^{3}$ O Grupo Coimbra de Universidades Brasileiras (GCUB) foi formalmente constituído como associação de dirigentes universitários em 27 de novembro de 2008, durante uma inesquecível solenidade acadêmica no Salão Nobre da Reitoria da Universidade de Coimbra. O GCUB é composto por universidades nacionais - federais, estaduais, confessionais e comunitárias - que reconhecem a instituição conimbricense como alma mater. Sua missão é promover a integração interinstitucional e internacional, mediante programas de mobilidade docente e discente, contribuindo para o processo de internacionalização soberana da rede universitária nacional com suas contrapartes estrangeiras. Por intermédio da prestigiosa Universidade de Coimbra, a mais antiga do mundo lusófono, o Grupo integra-se à linhagem das universidades arcanas do mundo ocidental, reunidas no Grupo Coimbra de Universidades Europeias, com o qual mantém, estatutariamente, vínculos de intercâmbio científico, pedagógico e cultural. As mais prestigiosas universidades brasileiras da atualidade compõem o conjunto de 50 instituições fundadoras, com 37 Universidades Federais (incluindo as instituições mais antigas e de maior porte), 06 Universidades Estaduais (incluindo as estaduais paulistas) e 07 Universidades Comunitárias e Confessionais (incluindo as principais PUC). O GCUB acolhe mais de um milhão de alunos matriculados na Graduação. Além disso, comporta a quase totalidade (98\%) dos programas de Pós-Graduação senso-estrito e dos Grupos de Pesquisa consolidados (94\%) no país (LIVRETO GCUB).

${ }^{4}$ Informação eletrônica.
} 
Cooperação vigente com a universidade portuguesa de destino dos estudantes e ter assinado Termo Aditivo específico para o Programa de Licenciaturas Internacionais; A instituição brasileira deverá ser membro de rede de universidades com vocação para cooperação internacional; A instituição brasileira deverá explicitar nos projetos a equivalência de Títulos/Áreas na universidade portuguesa e na universidade brasileira; A instituição brasileira deverá apresentar como coordenador um docente com título de doutor há pelo menos três anos, que detenha reconhecida competência na área e disponibilidade de tempo para as atividades acadêmicas e administrativas atinentes ao projeto; Não será permitida a candidatura de proposta cujo coordenador já seja coordenador de projeto vigente selecionado no Edital de 2011 do Programa de Licenciaturas Internacionais (PLI). Entretanto, o coordenador de projeto vigente poderá participar, apenas como membro da equipe, na nova proposta; Compor na equipe de trabalho pelo menos dois docentes doutores, além do coordenador (BRASIL, 2012, p. 5).

Cada projeto selecionado pode conter, no máximo sete, estudantes e as atividades destinadas ao Plano de Estudo são realizadas de acordo com o calendário universitário da Universidade do intercâmbio, tendo o suporte de um professor da universidade de origem e outro da universidade de destino.

Dentre as ações decorrentes deste edital, o qual foi editado e reeditado nos anos de 2010, 2011 e 2012, a CAPES criou o Programa de Licenciatura Internacional (PLI), cujo principal objetivo foi priorizar a melhoria do ensino nos cursos de licenciatura e a formação de professores, bem como:

[...]ampliar a formação de docentes para o ensino básico no contexto nacional; ampliar e dinamizar as ações voltadas à formação de professores, priorizando a formação inicial desenvolvida nos cursos de licenciatura; apoiar a formulação e implementação de novas diretrizes curriculares para a formação de professores, com ênfase no Ensino Fundamental e no Ensino Médio (BRASIL, 2012).

O PLI é um programa institucional, cuja participação dos estudantes dos cursos de Licenciatura ocorre por meio de seleção de projetos elaborados por docentes vinculados aos cursos de Química, Física, Matemática, Biologia, Português, Artes e Educação Física, que tenham assinado convênios de cooperação com universidades portuguesas. A seleção dos alunos que participarão do PLI é de responsabilidade da instituição proponente do projeto, e é destinado a estudantes que tenham cursado os primeiros semestres de seus respectivos cursos de licenciatura. O Programa possibilita, aos estudantes selecionados, receberem uma 
bolsa para continuarem seus estudos por um período de dois anos em uma das universidades portuguesas parceiras ${ }^{5}$.

Depois do seu regresso ao Brasil, para finalizarem a carreira na sua universidade de origem, depois de cumpridas todas as exigências acadêmicas, os estudantes formados que participaram do referido programa obterão duplo diploma de graduação, denominado graduação sanduíche.

Ao analisar os resultados dos editais dos projetos contemplados pelo programa nos anos de 2010, 2011, 2012, percebe-se um aumento na quantidade de procura pelo programa e, a cada edição, aumento no número de alunos participantes do PLI, como pode ser visto no quadro a seguir.

Quadro 1 - Número de projetos e alunos do PLI por edição

\begin{tabular}{|c|c|c|}
\hline $\begin{array}{c}\text { Programa de } \\
\text { Licenciatura } \\
\text { Internacional }\end{array}$ & $\begin{array}{c}\text { Projetos } \\
\text { contemplados }\end{array}$ & $\begin{array}{c}\text { Projetos } \\
\text { aprovados }\end{array}$ \\
\hline 2010-2012 & 30 & 27 \\
\hline 2011-2013 & 30 & 38 \\
\hline 2012-2014 & 40 & 64 \\
\hline
\end{tabular}

Fontes: BRASIL, 2010, 2011, 2012.

Ao analisar o Edital de 2011, vê-se que "a CAPES apoiará até 30 (trinta) projetos e cada projeto contemplará sete estudantes, totalizando 210 (duzentos e dez) estudantes" (BRASIL, 2011, p. 3).

No Edital de 2012, o texto mostra que a “CAPES apoiará até 40 (quarenta) projetos e cada projeto contemplará até 07 (sete) estudantes, totalizando 280 (duzentos e oitenta) bolsistas para este edital" (EDITAL, 2012, p. 3).

O programa tem cunho social e, devido isso, todo o candidato à bolsa deve ter cursado o Ensino Médio inteiramente e pelo menos dois anos do Ensino Fundamental em 
instituição pública brasileira, ou ter cursado parte do Ensino Médio em escolas privadas na condição de bolsista integral; porém, devem comprovar a baixa renda familiar (BRASIL, 2010, 2011, 2012).

Nas duas primeiras edições do PLI (2010 e 2011), o programa viabilizou o intercambio dos estudantes contemplados para a Universidade de Coimbra (UC) e, no terceiro ano (2012), o programa foi ampliado para mais dez universidades, sendo: Universidade Nova de Lisboa, Universidade da Beira Interior, Universidade do Algarve, Universidade de Aveiro, Universidade de Évora, Universidade de Lisboa, Universidade do Minho, Universidade do Porto, Universidade Técnica de Lisboa e Universidade Trás-os-Montes.

O PLI permite que os alunos, após realizarem os primeiros semestres de estudos nas universidades brasileiras, prossigam seus estudos, por um período de dois anos, em outro país e, ao finalizar os estudos, retornem ao Brasil para o término da formação na universidade de origem.

Entretanto, para a obtenção da dupla titulação, o aluno do PLI deve cumprir um número de créditos acadêmicos nas universidades em intercâmbio, totalizando um período de vinte quatro meses, ou quatro semestres letivos. No Ensino Europeu, esses números de créditos, European Credit Transfer and Accumulation System (Sistema Europeu de Acumulação e Transferência de Créditos - ECTS), é um sistema que mede as horas que o estudante tem que trabalhar para alcançar os objetivos do programa de estudos.

No programa em análise, o aluno deve obter um total de 120 ETCS para obter a dupla titulação, e no primeiro ano de estudos na universidade, o estudante deve ter, no mínimo, 48 ECTS. Caso não venha a atingir o mínimo de créditos para a aprovação, a continuidade dos estudos no segundo ano caberá à decisão da CAPES, devendo emitir um parecer pelo conselho formado por representantes da universidade portuguesa e da CAPES, com o apoio do Grupo Coimbra de Universidades Brasileiras (GCUB), com base no relatório de avaliação do aluno, elaborado pelo coordenador do projeto (EDITAL, 2012, p. 12).

Para a dupla titulação, após finalizado o intercâmbio, o estudante terá o diploma de Primeiro Ciclo (Licenciatura) na Universidade Portuguesa, e diploma de licenciado (cursos voltados para a formação de professores para a Educação Básica). Na Universidade Brasileira, o estudante deverá ter cumprido o plano de estudos formalmente aprovado pelos responsáveis na instituição de origem e na instituição de destino. 
Durante os vinte quatro meses de intercâmbio para a dupla titulação, o estudante cursa disciplinas da área de formação específica, além de disciplinas pedagógicas. Mas, caso o aluno, no final do intercambio, não atinja os 120 ECTS, a Universidade brasileira concederá equivalência automática àquelas disciplinas cursadas com aproveitamento, na modalidade de mobilidade internacional (EDITAL, 2012, p. 12).

Nesse caso, a arquitetura curricular leva em consideração a defasagem de períodos letivos entre o Brasil e o Espaço Europeu, onde aquele o ano acadêmico tem início normalmente em Março, e em Portugal, o Ensino Superior tem o ano letivo iniciado em Setembro. Assim, o primeiro ciclo será estruturado da seguinte forma:

\section{Quadro 2 - Arquitetura Curricular}

Caso 1 (ingressantes no 1을 semestre de 2009/2010/2011): Semestres 1, 2 e 3 na universidade brasileira.

Caso 2 (ingressantes no 2o semestre de 2009/2010/2011): Semestres 1 e 2 na universidade brasileira.

Formação Geral

Introdução à área específica de formação.

Caso 1- Semestres 4, 5, 6 e 7 na universidade portuguesa

Caso 2-Semestres 3, 4, 5 e 6 na universidade portuguesa

Formação na área específica

Disciplinas Pedagógicas

Complementos Curriculares optativos

Caso 1- Semestre 8 na Universidade brasileira

Caso 2- Semestres 7 e 8 na Universidade brasileira ${ }^{2}$

Conclusão de formação na área específica e pedagógica

Complementos Curriculares obrigatórios

Diplomação.

Fontes: BRASIL, 2012.

Para a realização dos intercâmbios que promovem a dupla titulação, o Ministério da Educação (MEC) não interfere nestes acordos, e não há exigência de credenciamento no 
ministério por parte das instituições. O MEC apenas exige que exista um convênio formal entre as universidades e o cumprimento de toda a carga horária do curso, bem como das atividades formativas do currículo brasileiro, além da equivalência dos estudos realizados fora do Brasil. As áreas de conhecimento contempladas no Programa são Artes, Educação Física, Educação, Ensino, Interdisciplinar, Letras, Biologia, Física, Matemática e Química. Segue o quadro com os projetos a equivalência de Títulos/Áreas na Universidade de Coimbra e na universidade brasileira.

Quadro 3 - Áreas

\begin{tabular}{|c|c|c|c|}
\hline $\begin{array}{l}\text { Universidade de } \\
\text { Coimbra }\end{array}$ & Área & $\begin{array}{l}\text { Universidade } \\
\text { brasileira }\end{array}$ & $\begin{array}{c}\text { Área de } \\
\text { concentração }\end{array}$ \\
\hline \multirow{4}{*}{$\begin{array}{c}\text { Licenciatura em } \\
\text { Ciências }\end{array}$} & Matemática & \multirow{4}{*}{$\begin{array}{c}\text { Bacharelado } \\
\text { Interdisciplinar em } \\
\text { Ciências e } \\
\text { Tecnologia ou } \\
\text { equivalente ou } \\
\text { Licenciatura em } \\
\text { Matemática, } \\
\text { Química, Física ou } \\
\text { Biologia }\end{array}$} & Ciências Exatas \\
\hline & Química & & \multirow{2}{*}{ Ciências da Matéria } \\
\hline & Física & & \\
\hline & Biologia & & Ciências da Vida \\
\hline $\begin{array}{c}\text { Licenciatura em } \\
\text { Letras }\end{array}$ & Português & $\begin{array}{l}\text { Bacharelado } \\
\text { Interdisciplinar em } \\
\text { Humanidades ou } \\
\text { equivalente ou } \\
\text { Licenciatura em } \\
\text { Letras (Português) }\end{array}$ & Estudos Literários \\
\hline $\begin{array}{c}\text { Licenciatura em } \\
\text { Artes }\end{array}$ & Estudos Artísticos & $\begin{array}{c}\text { Bacharelado } \\
\text { Interdisciplinar em } \\
\text { Artes ou } \\
\text { equivalente }\end{array}$ & $\begin{array}{l}\text { Música, Dança, } \\
\text { Teatro, Cinema }\end{array}$ \\
\hline $\begin{array}{c}\text { Licenciatura em } \\
\text { Ciências do } \\
\text { Desporto }\end{array}$ & Educação Física & $\begin{array}{c}\text { Bacharelado } \\
\text { Interdisciplinar em } \\
\text { Saúde ou } \\
\text { equivalente ou } \\
\text { Licenciatura em } \\
\text { Educação Física }\end{array}$ & Educação Física \\
\hline
\end{tabular}

Fontes: BRASIL, 2012. 
Ao analisar os resultados dos projetos contemplados nos anos de 2010/ 2011/ 2012 , foi possível criar um quadro a fim de descriminar a quantidade de projetos elaborados por áreas.

Quadro 4 - Número de áreas contempladas pelo PLI

\begin{tabular}{|c|c|c|c|}
\hline Áreas & 2010- 2012 & 2011- 2013 & 2012- 2014 \\
\hline Artes & 1 & 4 & 8 \\
\hline Educação Física & 3 & 4 & 15 \\
\hline Educação & 7 & 2 & - \\
\hline Ensino & 3 & - & - \\
\hline Interdisciplinar & 2 & 3 & 7 \\
\hline Letras & 2 & 7 & 5 \\
\hline Biologia & 4 & 8 & 5 \\
\hline Física & 2 & 3 & 2 \\
\hline Matemática & 1 & 1 & 5 \\
\hline Química & 2 & 1 & - \\
\hline Ciências & - & 5 & 64 \\
\hline Total & 27 & 38 & \\
\hline
\end{tabular}

Fontes: BRASIL, 2012.

Vale ressaltar que as áreas Interdisciplinares, Educação, Ciências e Ensino propiciam projetos com vieses para áreas conjuntas.

\section{Considerações Finais}

A descrição e análise do PLI permite identificar, em primeira instância, que houve boa receptividade entre as IES, as quais foram, também, aumentando a sua participação, à medida que foram publicados dois novos editais entre 2010 e 2012.

Entretanto, chama a atenção o fato de identificar que os referidos editais não apresentam mecanismos relacionados com a avaliação da efetividade da política, no que diz respeito à participação dos estudantes no exterior, nem apresentam mecanismos ou propostas de avaliação relacionadas com o impacto que este programa poderia estar causando no âmbito da implementação das diretrizes para a formação de professores.

Considera-se esta questão fundamental, em razão da necessidade de avaliar o impacto desta política em todos os sentidos, tendo em vista a análise e verificação da sua real efetividade para a formação futuros professores. Este aspecto sugere a necessidade de realizar pesquisas no interior das IES credenciadas para analisar como e quais são os critérios 
utilizados para avaliar a eficiência e eficácia do PLI, principalmente quando relacionados tais critérios com os impactos da globalização e da internacionalização da educação nesse contexto. Sabidamente, quando focado na questão da formação dos profissionais da educação para a lógica do mercado, este contexto coloca em xeque os princípios norteadores de uma formação ampliada para a formação de cidadãos críticos e comprometidos políticopedagogicamente com as transformações sociais necessárias à construção de uma sociedade justa e igualitária.

\section{REFERÊNCIAS:}

ALTBACH, P. G e KNIGHT, Jane. The Internationalization of Higher Education: Motivation and Realities. Journal Studies in International Education, vol. 11 No.3/4, Fall/Winter 2007 290-305.APPLE, M. Ideologia e currículo. 3. ed. Porto Alegre: ArtMed, 2007.

ALTBACH, P. G. Globalization and the university: myths and realities in an unequal world. Tertiary Education and Management, n. 1, 2004.

BRASIL. Coordenação de Aperfeiçoamento de Pessoal de Nível Superior. Edital no 135 Programa de Licenciaturas Internacionais.17 jun. 2010. Disponível em: <http:// www.capes.gov.br/cooperacao-internacional/multinacional/licenciaturasinternacionais/portugal>. Acesso em: 10 out 2014.

BRASIL. Coordenação de Aperfeiçoamento de Pessoal de Nível Superior. Edital № 8 Programa de Licenciaturas Internacionais. 16 mar. 2011. Disponível em: <http://www.capes.gov.br/cooperacao-internacional/multinacional/licenciaturas-internacionais/portugal>. Acesso em: 10 out 2014.

BRASIL. Coordenação de Aperfeiçoamento de Pessoal de Nível Superior. Edital no 8 Programa de Licenciaturas Internacionais. 7 mar. 2012. Disponível em: <http://www. capes.gov.br/cooperacao-internacional/multinacional/licenciaturas internacionais/portugal>. Acesso em: 10 out 2014.

BRASIL. Resultado do Edital 008/2012 - Programa Licenciaturas Internacionais. 14 jul. 2012. Disponível em: <http://www.capes.gov.br/cooperacaointernacional/multinacional/licenciaturas-internacionais/portugal>. Acesso em: 2 dez. 2014.

Resultado do Edital 035/2010 - Programa Licenciaturas Internacionais. 19 ago. 2010. Disponível em: <http://www.capes.gov.br/cooperacaointernacional/multinacional/licenciaturas-internacionais/portugal>. Acesso em: 2 dez. 2014.

SOUZA, J. M. D. J. A Internacionalização e a mobilidade na Educação Superior: O debate na América Latina. Revista de Iniciação Científica da FFC, 10. 2010. 
DRII. Diretoria de Relações Internacionais e Interinstitucionais. Disponível em: <http://www.dri.ufu.br/> Acesso em: 10 Abril. 2014.

KNIGHT, J; DE WIT, H. Internationalization of higher education: a conceptual framework. In Jane Knight and Hans de Wit (Ed.), Internationalization of higher education in Asia Pacific Countries. Amsterdam: European Association for International Education, 1997.

LIVRETO CBCU Disponível em: <http://www.grupocoimbra.org.br/coimbra/>. Acesso em: 20 Maio 2015

MIURA, I. K. O processo de internacionalização da Universidade de São Paulo: um estudo de três áreas de conhecimento. Anais do Encontro da Associação Nacional de Pós-graduação e Pesquisa em Administração, São Paulo- SP, 2009.

STALLIVIERI, L. Estratégias de Internacionalização das Universidades brasileiras. Caxias do Sul: Educs, 2004.

VIDAL, M.H.C. Atando nós que constroem redes... a expansão da rede Pitágoras no contexto da transnacionalização da educação. Dissertação (Mestrado em Educação- Pós-graduação em Educação, Universidade Federal de Uberlândia, Uberlândia, 2006.

ZAMBERLAM, J.; CORSO, G.; BOCCHI L.; FILIPPIN J.; KULKAMP W.; Estudantes Internacionais no processo Globalizador e na Internacionalização do Ensino Superior. Porto Alegre:

Solidus, 140p, 2009.

RECEBIDO EM 31 DE AGOSTO DE 2015.

APROVADO EM 27 DE JULHO DE 2016. 